\title{
MJN THE IMPACT OF UNIVERSITY AND HOSPITAL SUPPORT ON NURSING INTERN SATISFACTION
}

\author{
Abdullelah AI Thobaity ${ }^{1 *}$, Modi Owied AI Moteri² \\ ${ }^{1}$ Emergency Nursing, College of Applied Medical Sciences, Taif University, Saudi Arabia \\ ${ }^{2}$ Medical Surgical Nursing, Nursing department, College of Applied Medical Sciences, Taif University, Saudi Arabia \\ *Corresponding Author’sEmail: a.thobaity@tu.edu.com,Abdulellah.althobaity@hotmail.com
}

\begin{abstract}
The year-long clinical internship is important for undergraduate nursing students who are completing their four years of university study. It gives them an opportunity to work and practice the tasks assigned to them by different units and departments. To ensure that nursing students have a positive working environment, it is essential to examine the impact of support from both university faculty and hospital staff on nursing intern satisfaction. To assess this, cross-sectional surveys were distributed to nursing interns after they completed their internships. Researchers collected descriptive data and looked for correlations, later creating a model designed to measure direct or indirect impacts of faculty and hospital support on nursing intern satisfaction. This analysis, along with a regression model with goodness-of-fit test, was calculated using SPSS version 24 and AMOS version 24. In total, 138 students responded to the questionnaire. The majority of the participants were female, with 88 participants (63.8\%), while only 50 males (36.2\%) participated. Analysis showed a strong correlation between hospital support for nursing interns and interns' perception of a positive working environment, as well as a good correlation between positive working environment and overall nursing intern satisfaction. On the other hand, weak correlations show that university faculty had little perceived impact on whether or not nursing interns felt they worked in a positive environment. The study also confirmed that the hospital setting has impact significant on clinical positive environment. Knowing about what satisfies nursing interns helps nursing educators to devise internship programs that will improve the process for future cohorts.
\end{abstract}

Keywords: Nursing Intern, Satisfaction, Working environment, University Faculty

\section{INTRODUCTION}

The senior-year clinical internship is an important transitional phase that helps nursing students to become independent professional nurses. To have a successful internship, nursing interns a clinical training environment that allows them to acquire the necessary skills and competencies is needed (Murphy et al., 2012). These environments should be supported, cultivated, and maintained to ensure that nursing interns experience good-quality learning via their clinical practice (Leufer \& Cleary-Holdforth, 2020). Nursing interns must meet the clinical performance criteria set by their training programs to ensure the quality of training outcomes. However, it is evident in the literature that there are high rates of dissatisfaction among nursing interns result from unsupportive clinical learning environments; thus, we can explicate that further coordination between hospitals and universities is needed to improve the standard of nursing internship (Alharbi \& Alhosis, 2019). Besides the functional collaboration between their school and hospital placement, nursing interns anticipate a supportive clinical learning environment where they feel that they are an important part of the healthcare team (AlThiga et al., 2017).

Satisfaction plays an essential role in motivating nursing interns' performance. According to cognitive psychologists, it is a combined set of "psychological, physiological and environmental" conditions that motivates individuals to verbalize satisfaction about their work experience (Wright \& Cropanzano, 2000). In internships, satisfaction can be defined as a positive emotional state that interns possess towards their clinical training experiences (Papathanasiou, Tsaras \& Sarafis, 2014). There is a positive relationship between the 
quality of a given working environment and workers' satisfaction. Thus, for many applied studies, nursing intern satisfaction and clinical training environments have become closely linked (AlThiga et al., 2017; Shaban, Khater \& Akhu-Zaheya, 2012).

The clinical training environment involves two main dimensions: work and context. Work encompasses all the activities, tasks, and skills that are essential to the nursing profession, for instance, clinical procedures such as intravenous cannulation, medication administration and drug calculation; professional standards, such as ethics, values and communication; and cultural competence, such as understanding and respect of others' diversity. A study by Hickey revealed a lack of psychomotor skills to perform the required procedures among nursing interns (Hickey, 2009).

Context meanwhile includes the physical and social conditions surrounding a nursing intern in which their daily work occurs (Rozhkov, 2015). These physical conditions include the institutional structure and the objects inside it. Meanwhile, relevant social conditions include the intern's relationship to and expectations of their host institution, mentors, and colleagues (Shaban et al., 2012). Indeed, the relationship between the nursing staff and the nursing interns can impact the clinical learning experience (Alharbi \& Alhosis, 2019).

The recent changes in healthcare working environments have made it more difficult for nursing interns to adapt to their clinical training settings, resulting in dissatisfaction. In the literature, two main influences are detected on clinical learning (Tastan, Unver \& Hatipoglu, 2013). They were unsupportive nursing colleges and unsupportive clinical training settings (Changiz, Malekpour \& Zargham-Boroujeni, 2012). Unsupportive colleges and clinical training settings can interfere with nursing interns' coping approaches in real clinical situations.

The success of nurses' clinical training depends on appropriate interaction and cooperation between hospital staff and nursing colleges during the internship period (AlThiga et al., 2017; Jamshidi et al., 2016). However, many nursing programs fail to appreciate the importance of the environmental factors that influence nursing intern satisfaction and the many difficulties these can cause throughout the internship period (AlThiga et al., 2017). Furthermore, most studies that investigate the relationship between the clinical learning environment and nursing intern satisfaction have been based on the analysis on linear models (Admi et al.,
2018). It is crucial to vigorously assess the challenges that nursing interns face during the internship training period. Hence, we aimed in this study to examine the relationship between environmental factors and nursing intern satisfaction in greater depth. The three hypotheses below nursing intern were developed to test possible relationships between the variables.

$\mathbf{H}_{1}$ : Better support from nursing colleges will lead to more positive learning environments.

$\mathbf{H}_{2}$ : Better support from hospital settings will lead to more positive learning environments.

$\mathbf{H}_{3}$ : More positive learning environments will lead to increased nursing intern satisfaction.

\section{METHODOLOGY}

A cross-sectional design was used in path analysis for the related factors: hospital support, faculty support, positive environment and intern satisfaction. The participants in this study are nursing interns who completed all four years and passed all their university courses, as well as completing their internship year in hospitals in Saudi Arabia. The sample was a convenience sample, with questionnaires distributed to outgoing interns in May 2020, after they completed their internships in Ta' if city hospitals.

The questionnaire in this study was developed by the authors, who focused on asking about intern experiences with faculty and hospital support; the relative positivity of the hospital environment; and their satisfaction about the internship. After obtaining ethical approval from Ta'if University (No 41-00166) the data were collected via an online form. The data were then exported to the SPSS 24 software for management and clarification. Finishing this stage, we moved on to calculating means of variables and the correlations between them using Pearson's correlation analysis. The AMOS 24 software was used to perform the path analysis. The path model was designed with the following four variables: (1) support from university faculty; (2) support from hospital staff; (3) working environment positivity; and (4) overall satisfaction. The measurements taken to test the variables included $r=$ to measure the relationship between variables. The good fitness test for the developed model includes CMIN, RMR, GFI, RFI rho 1, and Standardized RMR (Kline, 2015).

\section{RESULTS}

The majority of survey respondents were female 88 $(63.8 \%)$ while 50 males $(36.2 \%)$ also participated. The 
means of the four variables, along with the standards deviations and the results of the correlation between them, are presented in Table 1. The overall satisfaction of interns was strongly positively correlated with working environment and hospital support $(r=0.61 ; p<0.01$; $p<0.01)$. The other positive, strong relationship was found between support from the hospital and the working environment $(r=0.62 ; p<0.01)$. A moderate positive relationship was detected in the study between university faculty support and other variables (hospital staff support; working environment positivity and overall satisfaction are the $\mathrm{r}$ values around between 0.32 to 0.36 with $p<0.01$ in all).

\section{Table 1: Correlation between Variables}

\begin{tabular}{|l|c|c|c|l|l|l|}
\hline Variables & Mean & SD & $\begin{array}{l}\text { Faculty } \\
\text { Support }\end{array}$ & $\begin{array}{l}\text { Hospital } \\
\text { Support }\end{array}$ & $\begin{array}{l}\text { Working } \\
\text { Environmen } \\
\text { Positivity }\end{array}$ & $\begin{array}{l}\text { Overall } \\
\text { Satisfaction }\end{array}$ \\
\hline Faculty Support & 3.23 & 0.54 & 1.000 & & & \\
\hline Hospital Support & 3.24 & 0.63 & $0.329^{* *}$ & 1.000 & & \\
\hline $\begin{array}{l}\text { Working } \\
\text { Environment } \\
\text { Positivity }\end{array}$ & 2.66 & 0.80 & $0.361^{* *}$ & $0.615^{* *}$ & 1.000 & \\
\hline $\begin{array}{l}\text { Overall } \\
\text { Satisfaction }\end{array}$ & 3.27 & 0.56 & $0.317^{* *}$ & $0.539^{* *}$ & $0.607^{* *}$ & 1.000 \\
\hline
\end{tabular}

**Correlation is significant at the 0.01 level (2-tailed)

Figure 1 demonstrates the path analysis for the effects of both hospital and faculty support on overall satisfaction. The findings of fitness were: $\mathrm{CMIN}=0.69$., $\mathrm{DF}=1 ., \mathrm{P}=0.41 ; \mathrm{RMR}=0.01, \mathrm{GFI}=0.99 ., \mathrm{RFI}$ rho1 $=$ 0.98 ., Standardized RMR $=0.0124$ which all indicate that the model has accepted goodness of fit.

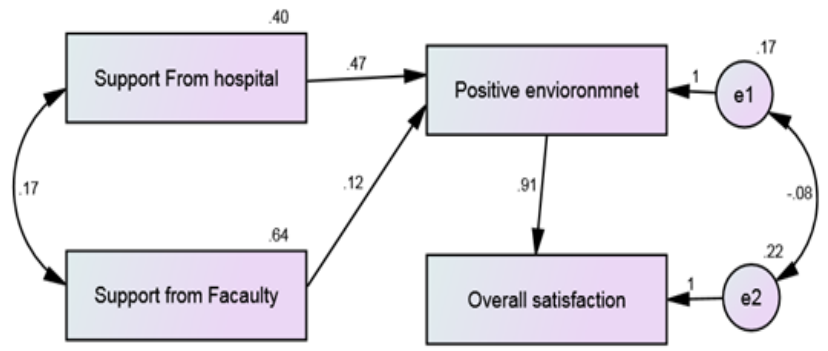

Figure 1: Path Analysis

The path coefficient between working environment positivity and hospital support was 0.47 (unstandardized, standard error (SE) 0.06), and the path was statistically significant $(p<0.001)$. This supports Hypothesis 3 , that "Better support from hospital setting will lead to a more positive learning environment." The path coefficients between satisfaction and positive environment, as predicted, significantly support $\mathrm{H} 3$; they equal 0.91 ; $\mathrm{SE}=0.12$ with $p<0.01$. However, the first hypothesis, that faculty support will improve the positivity of the intern working environments, is not conclusively supported by our study, as the regression weight is 0.12 , which is too close to the value 0 ; therefore, this hypothesis is rejected in this study. Table 2 illustrates the regression weights between all the variables.

\section{Table 2: Regression Weights}

\begin{tabular}{|l|l|c|c|c|c|}
\hline $\begin{array}{l}\text { Dependent } \\
\text { variables }\end{array}$ & $\begin{array}{l}\text { Independent } \\
\text { variables }\end{array}$ & $\begin{array}{c}\text { Regression } \\
\text { Weight }\end{array}$ & S.E. & C.R. & $\boldsymbol{P}$ \\
\hline $\begin{array}{l}\text { Positive } \\
\text { Environment }\end{array}$ & Hospital Support & 0.47 & 0.06 & 8.212 & $<0.001$ \\
\cline { 2 - 6 } & University Support & 0.12 & 0.04 & 2.795 & 0.005 \\
\hline $\begin{array}{l}\text { Overall } \\
\text { Satisfaction }\end{array}$ & $\begin{array}{l}\text { Positive } \\
\text { Environment }\end{array}$ & 0.91 & 0.12 & 7.793 & $<0.001$ \\
\hline
\end{tabular}

Note $C R=$ critical ratio $\cdot S E=$ standard error

\section{DISCUSSION}

Nursing is a clinical discipline that requires the acquisition of clinical skills and knowledge. Internship experience allows interns to practice their learned skills in the real-life environment of a clinical setting. This will definitely support the development of the necessary clinical skills (Smith, 2006). However, internship programs usually also require the student to be placed in a learning environment that is separate from the college, which may cause nursing interns to have a feeling of isolation. A positive clinical learning environment can minimize that isolation and encourage nursing interns to practice their learned skills. A successful internship experience for nursing interns depends on interaction with both hospital staff and their educational institution. A detached or disassociated relationship between the institutions where the clinical training and planning are taking place can negatively affect nursing interns' transition to independent professional nurses (Eick, Williamson \& Heath, 2012; Leufer \& Cleary-Holdforth, 2020; Rozhkov, 2015; Shaban et al., 2012).

This study was conducted to investigate the relationship between environmental factors and nursing intern satisfaction during clinical internships. The study confirmed a positive relationship between nursing colleges and the clinical learning environment. Specifically, findings revealed that perceived support from nursing college makes nursing interns more satisfied with their internship training experience. The finding supported Hypothesis 1 that better support from nursing colleges will lead to positive learning environment. These results are in line with findings in the literature (Serrano-Gallardo et al., 2016). Previous studies showed that nursing intern satisfaction with their learning experience is dependent on their relationship with their universities (Chan, 2001). Particular attention 
to maintain collaborations between college and hospital staff should be guaranteed.

The study also confirmed a positive relationship between hospital support and clinical learning environment. The relationship of nursing interns with the healthcare team they work under is a key element in promoting interns' self-confidence and satisfaction, consequently enhancing knowledge and skill acquisition (ibid). Clinical setting plays an important role in the clinical training experience. Indeed, studies have repeatedly confirmed that clinical settings which provided opportunities for nursing interns to learn while maintaining pro-social working environments were found to be a significant predictor of clinical training satisfaction (Eick et al., 2012; Löfmark \& Wikblad, 2001; Midgley, 2006). Furthermore, promoting nursing interns' sense of autonomy as they perform different tasks and procedures, as well as providing support and feedback, is more likely to facilitate the learning process and ultimately increase intern satisfaction (Eick et al., 2012). Some skills required by the hospitals are very essential and hospital administrations ensure that nursing interns are involved and aware about them, such as disaster preparedness; quality controls; patient safety, and updates to the field of nursing (Al Thobaity et al., 2019; Al Thobaity et al., 2015; Abdullelah Al Thobaity, Plummer \& Williams, 2017; Abdulellah Al Thobaity, Williams \& Plummer, 2016).

\section{Limitations}

In this study, nursing interns were recruited through a single institution. Therefore, the findings should be utilized with caution. Although the sample size was enough to detect statistically significant associations between the variables, a larger sample size is preferable for future studies. Another limitation of this study is the study design. The crosssectional nature of the design does not allow evaluation of cause and effect. Perhaps utilizing a prospective cohort study design would be valuable to detect changes in intern training satisfaction.

\section{CONCLUSION}

As perceived support from both university and clinical settings have positive correlations with nursing intern experience. It is very important to emphasize them by maintaining effective communication and collaboration between university and hospital staff during the internship period. If nursing interns are satisfied with their clinical learning experience, they are more likely to be motivated to learn than if they are not satisfied. Knowing about what satisfies nursing interns, in turn, will help nursing educators as they design the next generation of nursing internship programs. More understanding of the importance of maintaining good relationships between nursing colleges and clinical training settings can help them improve nursing intern experiences and outcomes.

\section{Conflict of Interests}

The authors declare that they have no conflict of interest.

\section{ACKNOWLEDGEMENT}

The authors are thankful to the institutional authority for completion of the work.

\section{REFERENCES}

Admi, H., Moshe-Eilon, Y., Sharon, D. \& Mann, M. (2018). Nursing students' stress and satisfaction in clinical practice along different stages: A cross-sectional study. Nurse Education Today, 68, pp 86-92.

Al Thobaity, A., Alamri, S., Plummer, V. \& Williams, B. (2019). Exploring the necessary disaster plan components in Saudi Arabian hospitals. International Journal of Disaster Risk Reduction, 41, 101316.

Al Thobaity, A., Plummer, V., Innes, K. \& Copnell, B. (2015). Perceptions of knowledge of disaster management among military and civilian nurses in Saudi Arabia. Australasian Emergency Nursing Journal, 18(3), pp 156-164.

Al Thobaity, A., Plummer, V. \& Williams, B. (2017). What are the most common domains of the core competencies of disaster nursing? A scoping review. International Emergency Nursing, 31, pp 64-71.

Al Thobaity, A., Williams, B. \& Plummer, V. (2016). A new scale for disaster nursing core competencies: development and psychometric testing. Australasian Emergency Nursing Journal, 19(1), pp 11-19. 
Alharbi, A.R. \& Alhosis, K.F. (2019). The challenges and difficulties of the nursing interns during their clinical internship in Qassim Region, Saudi Arabia. Saudi Journal for Health Sciences, 8(1), pp 6-11.

AlThiga, H., Mohidin, S., Park, Y.S. \& Tekian, A. (2017). Preparing for practice: Nursing intern and faculty perceptions on clinical experiences. Medical Teacher, 39(sup1), S55-S62.

Chan, D.S. (2001). Combining qualitative and quantitative methods in assessing hospital learning environments. International Journal of Nursing Studies, 38(4), pp 447-459.

Changiz, T., Malekpour, A. \& Zargham-Boroujeni, A. (2012). Stressors in clinical nursing education in Iran: A systematic review. Iranian Journal of Nursing and Midwifery Research, 17(6), pp 399-407.

Eick, S.A., Williamson, G.R. \& Heath, V. (2012). A systematic review of placement-related attrition in nurse education. International Journal of Nursing Studies, 49(10), pp 1299-1309.

Hickey, M.T. (2009). Preceptor perceptions of new graduate nurse readiness for practice. Journal for Nurses in Professional Development, 25(1), pp 35-41.

Jamshidi, N., Molazem, Z., Sharif, F., Torabizadeh, C. \& Najafi Kalyani, M. (2016). The challenges of nursing students in the clinical learning environment: A qualitative study. The Scientific World Journal, 2016, 1846178.

Kline, R.B. (2015). Principles and Practice of Structural Equation Modeling. USA: Guilford publications.

Leufer, T. \& Cleary-Holdforth, J. (2020). Senior Nursing Students' Perceptions of Their Readiness for Practice Prior to Final Year Internship: Part 2-A Qualitative Perspective. Dimensions of Critical Care Nursing, 39(2), pp 81-90.

Löfmark, A. \& Wikblad, K. (2001). Facilitating and obstructing factors for development of learning in clinical practice: a student perspective. Journal of Advanced Nursing, 34(1), pp 43-50.

Midgley, K. (2006). Pre-registration student nurses perception of the hospital-learning environment during clinical placements. Nurse Education Today, 26(4), pp 338-345.

Murphy, F., Rosser, M., Bevan, R., Warner, G. \& Jordan, S. (2012). Nursing students' experiences and preferences regarding hospital and community placements. Nurse Education Today, 12(3), pp 170-175.

Papathanasiou, I.V., Tsaras, K. \& Sarafis, P. (2014). Views and perceptions of nursing students on their clinical learning environment: Teaching and learning. Nurse Education in Practice, 34(1), pp 57-60.

Rozhkov, M. (2015). Workplace Context and its Effect on Individual Competencies and Performance in Work and Project Teams. The Hong Kong Polytechnic University, Hong Kong.

Serrano-Gallardo, P., Martínez-Marcos, M., Espejo-Matorrales, F., Arakawa, T., Magnabosco, G.T. \& Pinto, I.C. (2016). Factors associated to clinical learning in nursing students in primary health care: an analytical crosssectional study. Revista Latino-Americana De Enfermagem, 24(0):e2803.

Shaban, I. A., Khater, W. A. \& Akhu-Zaheya, L. M. (2012). Undergraduate nursing students' stress sources and coping behaviours during their initial period of clinical training: A Jordanian perspective. Nurse Education in Practice, 12(4), pp 204-209.

Smith, J.S. (2006). Exploring the challenges for nontraditional male students transitioning into a nursing program. Journal of Nursing Education, 45(7), pp 263-269.

Tastan, S., Unver, V. \& Hatipoglu, S. (2013). An analysis of the factors affecting the transition period to professional roles for newly graduated nurses in Turkey. International Nursing Review, 60(3), pp 405-412.

Wright, T.A. \& Cropanzano, R. (2000). Psychological well-being and job satisfaction as predictors of job performance. Journal of Occupational Health Psychology, 5(1), pp 84-94. 